\title{
A Supramolecular Porous Organic Cage Platform Promotes Electrochemical Hydrogen Evolution from Water Catalyzed by Cobalt Porphyrins
}

\author{
Peter T. Smith, ${ }^{[a]}$ Bahiru Punja Benke, ${ }^{[b]}$ Lun An, ${ }^{[a]}$ Younghoon Kim, ${ }^{[b, c]}$ Kimoon Kim, $\left.{ }^{*[b}, c\right]$ and \\ Christopher J. Chang*[a, d]
}

[a] Department of Chemistry, University of California, Berkeley, Chemical Sciences Division, Lawrence Berkeley National Laboratory, Berkeley, CA 94720-1460 (USA), chrischang@berkeley.edu

[b] Center for Self-assembly and Complexity (CSC), Institute for Basic Science (IBS), Pohang 37673 (Republic of Korea), kkim@postech.ac.kr

[c] Department of Chemistry, Pohang University of Science and Technology, Pohang 37673 (Republic of Korea)

[d] Department of Molecular and Cell Biology, University of California, Berkeley, Berkeley, CA 94720-1460 (USA)

We dedicate this paper to Prof. Jean-Michel Savéant.

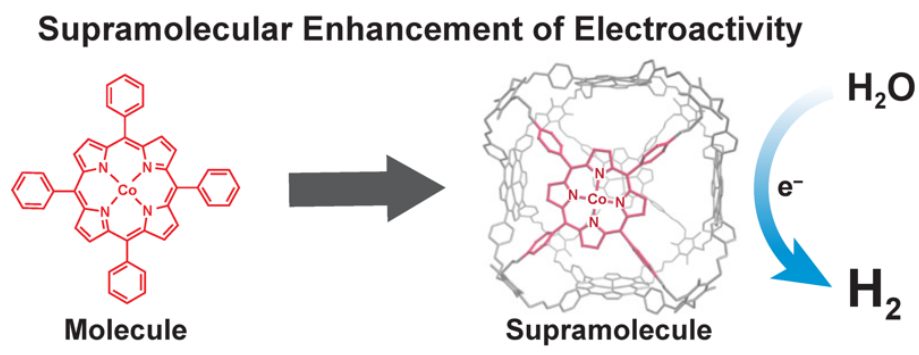

\begin{abstract}
We report a supramolecular porous organic cage platform composed of cobalt porphyrins for catalyzing the electrochemical hydrogen evolution reaction (HER) from water at neutral $\mathrm{pH}$. Owing to its permanent porosity, the supramolecular structure yields a catalyst film with a 5-fold increase in the number of electrochemically active cobalt atoms and an improvement in Tafel slope from $170 \mathrm{mV} /$ decade to $119 \mathrm{mV} /$ decade compared to a planar cobalt porphyrin analog, reaching activities over 19,000 turnovers for HER over a 24-hour period with $100 \%$ Faradaic efficiency.
\end{abstract}

The generation of high-purity hydrogen gas from renewable sources for use as a fuel or synthetic feedstock is an attractive alternative over conventional energyintensive and environmentally harmful processes including natural gas reforming. ${ }^{[1]}$ In this context, water is an abundant and sustainable source of protons that can be reduced to form hydrogen, and the development of catalysts for the electrochemical hydrogen evolution reaction (HER) using earth-abundant metals has been the subject of intense research. ${ }^{[2]}$ In particular, electrochemical HER using a variety of cobalt complexes has been thoroughly investigated, ${ }^{[3]}$ and cobalt porphyrins specifically have been shown to be efficient hydrogen evolving catalysts in homogeneous organic or aqueous conditions ${ }^{[4]}$ as catalyst films ${ }^{[5]}$ and even within artificial metalloenzymes. ${ }^{\left[{ }^{[6}\right.}$ More broadly, porphyrin-based catalysts have proven to be privileged scaffolds for many small-molecule activation reactions owing to facile synthetic tuning of the porphyrin electronics and the associated outer-coordination sphere. ${ }^{[7]}$ In materials platforms for energy catalysis, a common strategy for tuning catalytic activity is altering the nanostructure of the electrode material in an effort to elucidate how different shapes, sizes, or assemblies can influence the active sites. ${ }^{[8]}$ At even smaller length scales, the supramolecular architecture of electrochemical molecular catalysts at the electrode can enable tuning of catalytic activity in confined spaces, ${ }^{[9]}$ with extended framework materials being tailored matrices using a similar approach ${ }^{\left[{ }^{[0]}\right.}$ As part of a major thrust in our research program in unifying design strategies from molecular, materials, and biological catalysts for sustainable electrosynthesis and photosynthesis, ${ }^{[11]}$ we report here an investigation into the effects of embedding cobalt porphyrin electrocatalysts for HER within a supramolecular porous organic cage.

Based on recent work from our laboratories using porous supramolecular architectures to enhance the electrochemical activity and selectivity of embedded 

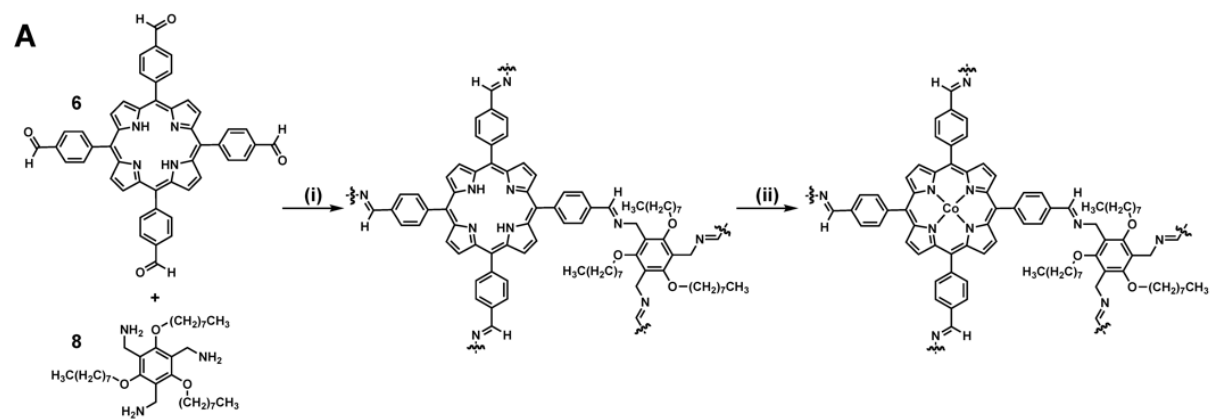

B

Scheme 1. (A) Synthetic scheme for the preparation of the porous organic cage Co-PB-1(8). (i) Trifluoroacetic acid (cat.), $\mathrm{CHCl}_{3}, 55^{\circ} \mathrm{C}, 12 \mathrm{~h}$; (ii) $\mathrm{CoCl}_{2}, 2,6$-lutidine, THF, $70^{\circ} \mathrm{C}, 12 \mathrm{~h}$. (B) Comparison of a model of the porous organic cage catalyst Co-PB-1(8) (left) and its monomeric analog Co-TPP (right). Alkyl chains and hydrogen atoms are omitted in the molecular model for clarity.

molecular catalysts for $\mathrm{CO}_{2}$ reduction reaction $\left(\mathrm{CO}_{2} \mathrm{RR}\right)$ and $\mathrm{O}_{2}$ reduction reaction (ORR) processes, ${ }^{[9 i, 9 j]}$ we reasoned that electrochemical HER would likewise benefit from permanent porosity to more efficiently expose molecular active sites. Indeed, we have focused on exploring porous organic cages as catalyst platforms owing to the ability to rationally design and synthesize supramolecules built from robust covalent linkages that feature permanent porosity. ${ }^{[12]}$ These architectures can provide both chemical and electrochemical stability, ${ }^{[13]}$ effective gas adsorption and separation properties, ${ }^{[14]}$ and promote gas solubility in the liquid phase. ${ }^{[15]}$ We have previously demonstrated the utility of various derivatives of the porphyrin box platform as synthetic ion channels, ${ }^{[16]}$ building blocks for metal-organic frameworks ${ }^{[17]}$ materials for photoinduced charge separation, ${ }^{[18]}$ and catalysts for electrochemical $\mathrm{CO}_{2}$ or $\mathrm{O}_{2}$ reduction. ${ }^{\left[{ }^{i j}, 9 j\right]}$ These collective efforts establish porphyrin-based porous organic cages as a versatile and modular system where metal and strut substitutions can enable a broad range of applications. ${ }^{[19]}$

To start, the free-base porphyrin box was first obtained by imine condensation between six tetra(formylphenyl)porphyrins and eight triamine linkers bearing solubilizing $\mathrm{C}_{8} \mathrm{H}_{17}$ alkyl groups (Scheme 1). Successful and complete metalation of all six porphyrin moieties in the porphyrin box using $\mathrm{CoCl}_{2}$ to obtain CoPB-1(8) was confirmed using MALDI mass spectrometry and UV/Vis spectroscopy (Figure S1-S2). Gas sorption studies of Co-PB-1(8) show permanent porosity and indicate a Brunauer-Emmett-Teller surface area of 519 $\mathrm{m}^{2} / \mathrm{g}$ (Figure S3).

In order to utilize the porous organic cage system with an aqueous electrolyte, the supramolecular Co-PB1(8) catalyst was heterogenized by drop-casting onto a glassy carbon working electrode that had first been coated with carbon nanotubes to enhance conductivity. Linear sweep voltammetry (LSV) of this heterogeneous Co-PB-1(8) electrode in $1 \mathrm{M} \mathrm{pH} 7$ phosphate buffer shows a large cathodic current enhancement when scanning beyond $-0.45 \mathrm{~V}$ vs. the reversible hydrogen electrode (RHE), suggesting catalytic proton reduction to hydrogen (Figure 1). For comparison, we investigated CoTPP as an electrochemical HER catalyst under the same conditions since it is the base molecular unit of the supramolecular Co-PB-1(8) architecture. Six molar equivalents of Co-TPP were deposited onto the electrode in order to normalize to the number of Co centers in the Co-PB-1(8) and Co-TPP heterogeneous catalyst films. Accordingly, LSV of this Co-TPP electrode shows a much weaker current enhancement with an onset potential for HER shifted slightly more negative compared to Co-PB1(8). This enhanced catalytic response is observed despite the supramolecular catalyst possessing electronwithdrawing imine groups that may reduce the nucleophilicity of the metal center and thus hinder catalysis, as observed in reported scaling relationships. ${ }^{[20]}$

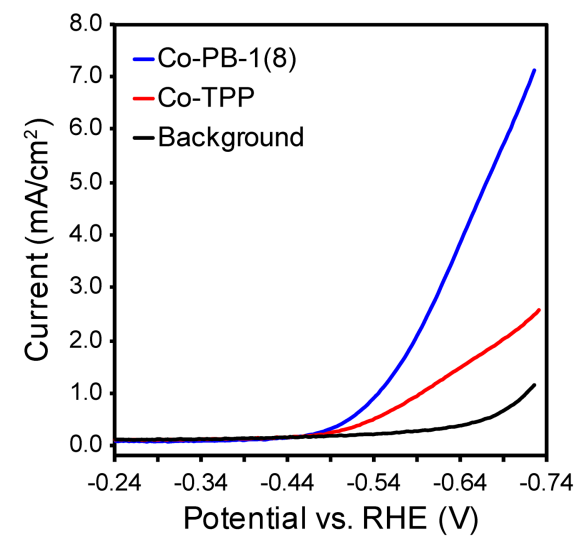

Figure 1. LSV traces for supramolecular porous cage catalyst Co-PB-1(8) (blue), its planar molecular analog Co-TPP (red), and electrode background (black) obtained in $1 \mathrm{M} \mathrm{pH} 7$ phosphate buffer saturated with $\mathrm{N}_{2}$.

Notably, Tafel analyses plotted in Figure 2 indicate that the supramolecular Co-PB-1(8) catalyst displays improved kinetics compared to the molecular Co-TPP congener. Co-PB-1(8) exhibits a Tafel slope of 119 $\mathrm{mV} / \mathrm{dec}$, which is in agreement with the theory that a single electron transfer to a proton from water is ratedetermining. ${ }^{[21]}$ In contrast, Co-TPP has a larger Tafel 
slope of $170 \mathrm{mV} /$ dec. We attribute this observed difference to inferior electron transfer throughout the CoTPP catalyst film and/or to a lower local concentration of water within the film relative to the Co-PB-1(8) system. We speculate that the structural porosity of Co-PB-1(8) facilitates the delivery of both electrons and protons to the active Co centers. Indeed, heterogeneous molecular electrochemical catalysts commonly suffer from large Tafel slopes, indicating that the initial electron transfer is greatly hindered and/or that substrate adsorption or product desorption steps are slow. ${ }^{[22]}$ As such, embedding the catalyst into a supramolecular architecture may accelerate this rate-limiting step by facilitating charge, electrolyte, and substrate transport.

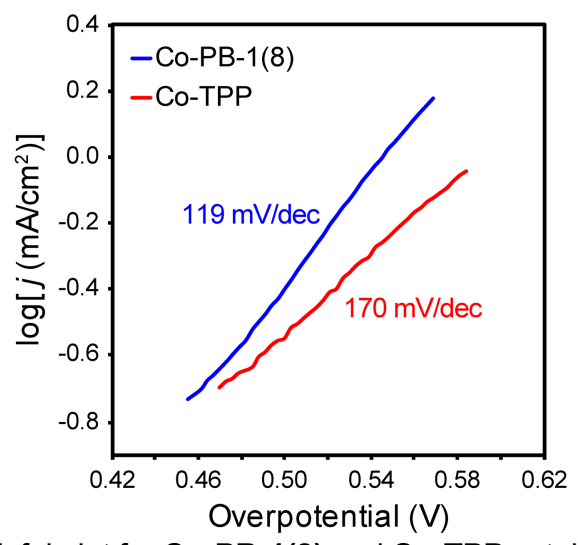

Figure 2. Tafel plot for Co-PB-1(8) and Co-TPP catalysts. Each catalyst electrode was prepared by depositing $13.8 \mathrm{nmol} / \mathrm{cm}^{2}$ of Co centers (2.3 nmol/cm ${ }^{2}$ of hexa-cobalt Co-PB-1(8) and 13.8 $\mathrm{nmol} / \mathrm{cm}^{2}$ of mono-cobalt Co-TPP).

We next analyzed the electrochemically active surface areas of the Co-PB-1(8) and Co-TPP heterogeneous electrodes by measuring the scan rate dependence of the reversible $\mathrm{Co}^{\prime \prime \prime} / \mathrm{Co}$ "l redox couple observed at $0.76 \mathrm{~V}$ vs. RHE for both Co-PB-1(8) and CoTPP in $1 \mathrm{M} \mathrm{pH} 7$ phosphate buffer (Figure 3A, B). Both catalyst films were prepared by depositing $13.8 \mathrm{nmol} / \mathrm{cm}^{2}$
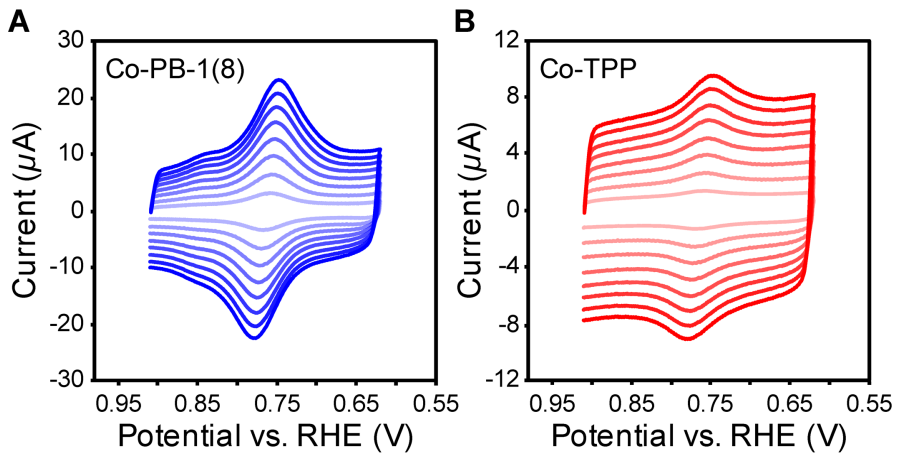

of Co centers $\left(2.3 \mathrm{nmol} / \mathrm{cm}^{2}\right.$ of Co-PB-1(8) and 13.8 $\mathrm{nmol} / \mathrm{cm}^{2}$ of Co-TPP). Variation of the cathodic and anodic peak currents with the scan rate was linear for both catalysts, (Figure 3C, D) indicating catalyst immobilization and reversible electron transfer. ${ }^{[23]}$ From these data, we calculated that the Co-PB-1(8) electrode had $1.0 \pm 0.1$ $\mathrm{nmol} / \mathrm{cm}^{2}$ of electrochemically active Co centers compared to $0.2 \pm 0.05 \mathrm{nmol} / \mathrm{cm}^{2}$ in the Co-TPP electrode. These values correspond to $1.4 \%$ of Co centers being electroactive in the Co-TPP film and $7.2 \%$ of the Co centers are electroactive in the Co-PB-1(8) film, resulting in a 5-fold enhancement in electrochemically active surface area observed for the supramolecular CoPB-1(8) catalyst over the molecular Co-TPP control, reinforcing that the permanent porosity derived from supramolecular incorporation of the Co-porphyrin unit can contribute to making the active sites more accessible in the film. Indeed, aggregation of planar macrocyclic catalysts has been shown to greatly hinder electrocatalytic activity. ${ }^{[24]}$

With these data in hand, we performed controlled potential electrolysis experiments with both Co-PB-1(8) and Co-TPP heterogeneous electrodes as HER electrocatalysts $\left(13.8 \mathrm{nmol} / \mathrm{cm}^{2}\right.$ Co deposited for each) in $1 \mathrm{M} \mathrm{pH} 7$ phosphate buffer. A potential of $-0.6 \mathrm{~V}$ vs. RHE was applied for $24 \mathrm{~h}$, and Co-PB-1(8) and Co-TPP consumed $114 \mathrm{C}$ and $52 \mathrm{C}$ of charge, respectively (Figure 4). Analyzing the headspace after each experiment by gas chromatography revealed that both catalysts gave ca. 100\% Faradaic efficiency for HER, with Co-PB-1(8) producing more than twice the amount of $\mathrm{H}_{2}$ compared to Co-TPP (14.0 mL vs. $6.6 \mathrm{~mL}$ of hydrogen). For Co-PB$1(8)$, these results correspond to a turnover number (TON) of 19,030 [TON per electroactive Co $\left(T^{T O N} \mathrm{NAA}_{\mathrm{A}}\right)=$ $262,660]$ and an average turnover frequency (TOF) of $0.22 \mathrm{~s}^{-1}$ [TOF per electroactive Co $\left(\right.$ TOF $\left._{\mathrm{EA}}\right)=3.04 \mathrm{~s}^{-1}$ ]. For Co-TPP, these data give a TON of $8,710\left(T_{O N}{ }_{E A}=\right.$ $601,090)$ and an average TOF of $0.10 \mathrm{~s}^{-1}($ TOFEA $=6.96$ $\mathrm{s}^{-1}$ ). The data support the notion that the supramolecular structure allows for more of the deposited catalytic cobalt

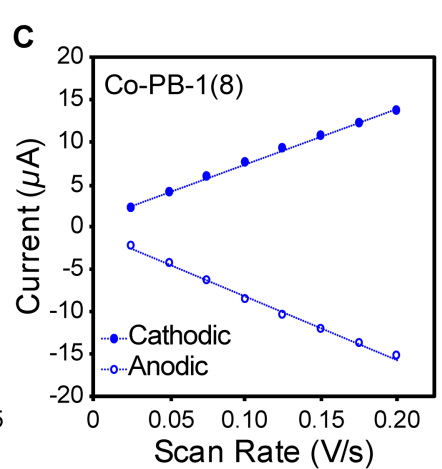

Figure 3. Scan rate dependence from 0.025 to $0.2 \mathrm{~V} / \mathrm{s}$ of the Co"l'/Co"l redox couple for supramolecular Co-PB-1(8) (A) and molecular Co-TPP (B) catalyst films in $1 \mathrm{M} \mathrm{pH} 7$ phosphate buffer saturated with $\mathrm{N}_{2}$. Each catalyst electrode was prepared by depositing $13.8 \mathrm{nmol} / \mathrm{cm}^{2}$ of Co centers (2.3 nmol/ $\mathrm{cm}^{2}$ of Co-PB-1(8) and $13.8 \mathrm{nmol} / \mathrm{cm}^{2}$ of Co-TPP). The corresponding cathodic and anodic peak currents are plotted against the scan rate in (C) for Co-PB-1(8) and in (D) for Co-TPP. 
porphyrin moieties to participate in electrochemical HER. Normalizing to the number of electroactive Co centers reveals that the monomeric Co-TPP catalyst can outperform Co-PB-1(8) in terms of TONEA and TOFEA; however, in a practical sense we emphasize the performance of the entire catalyst film owing to the importance of the electrode assembly and the challenges of achieving a high percentage of active metal centers when heterogenized. Recently, various catalyst immobilization strategies or additives have shown how influential these can be to the electrocatalyst activity, ${ }^{[25]}$ and supramolecular incorporation to achieve permanent porosity offers a viable strategy to improve catalyst film design. We can also attribute this slight difference in the intrinsic catalytic activity by the presence of electronwithdrawing imine groups present in the Co-PB-1(8) catalyst, which may reduce the nucleophilicity of the metal center compared to Co-TPP at the same applied potential. Nevertheless, the supramolecular architecture enables the Co-PB-1(8) catalyst to electrochemically generate significantly more hydrogen than the monomeric analogue Co-TPP, under identical conditions and at an overpotential of $0.6 \mathrm{~V}$, which compares favorably with canonical molecular HER catalysts under neutral aqueous conditions. ${ }^{[2 a, 3 f, 3 r, 4,6 a]}$

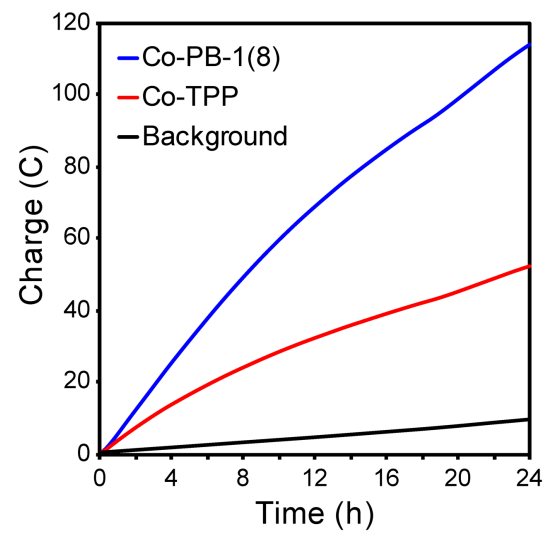

Figure 4. Charge accumulation during long-term controlled potential electrolysis experiments with supramolecular Co-PB1(8) (blue), molecular Co-TPP (red), and electrode background (black) at $-0.6 \mathrm{~V}$ vs. RHE in $1 \mathrm{M} \mathrm{pH} 7$ phosphate buffer saturated with Ar. Each catalyst electrode was prepared by depositing $13.8 \mathrm{nmol} / \mathrm{cm}^{2}$ of Co centers $\left(2.3 \mathrm{nmol} / \mathrm{cm}^{2}\right.$ of Co-PB-1(8) and $13.8 \mathrm{nmol} / \mathrm{cm}^{2}$ of Co-TPP).

To close, we have established that incorporation of molecular cobalt porphyrin catalysts into supramolecular porous organic cages can enhance their ability to catalyze electrochemical HER from water at neutral $\mathrm{pH}$, with turnover numbers reaching over 19,000 and stability for at least 24 hours. Tafel analysis reveals that electron transfer and/or proton availability are superior for the supramolecular Co-PB-1(8) catalyst over its molecular Co-TPP counterpart, and the measured electrochemically active surface areas show that the Co-PB-1(8) electrode displays more than 5 times as many electroactive Co centers over Co-TPP. These data further establish this supramolecular approach as an effective strategy to enhance catalytic activity of molecular electrocatalysts. We anticipate that the versatility of porous organic cages as a supramolecular platform for developing tunable and efficient catalysts will continue to expand, particularly for reactions that can be effected by sustainable electrical and/or light energy input.

\section{Acknowledgements}

Financial support for energy catalysis, particularly synthesis and electrochemical studies, in the C.J.C. laboratory was provided by the Director, Office of Science, Office of Basic Energy Sciences, and the Division of Chemical Sciences, Geosciences, and Bioscience of the U.S. Department of Energy at Lawrence Berkeley National Laboratory (Grant No. DE-AC02$05 \mathrm{CH} 11231$ ). Synthesis and characterization work performed in the K.K. laboratory was supported by the Institute for Basic Science (IBS) in Rep. of Korea (Grant No. IBS-R007-D1). C.J.C is a CIFAR Senior Fellow. P.T.S. acknowledges support from the National Science Foundation Graduate Research Fellowship Program.

\section{Conflict of Interest}

The authors declare no conflict of interest.

\section{References}

[1] J. A. Turner, Science 2004, 305, 972-974.

[2] a) V. S. Thoi, Y. Sun, J. R. Long, C. J. Chang, Chem. Soc. Rev. 2013, 42, 2388-2400; b) J. R. McKone, S. C. Marinescu, B. S. Brunschwig, J. R. Winkler, H. B. Gray, Chem. Sci. 2014, 5, 865-878; c) I. Roger, M. A. Shipman, M. D. Symes, Nat. Rev. Chem. 2017, 1, 0003; d) Z.

Thammavongsy, I. P. Mercer, J. Y. Yang, Chem. Commun. 2019, 55, 10342-10358; e) I. Bhugun, D. Lexa, J. M. Saveant, J. Am. Chem. Soc. 1996, 118, 3982-3983.

[3] a) X. Hu, B. S. Brunschwig, J. C. Peters, J. Am. Chem. Soc. 2007, 129, 8988-8998; b) L. A. Berben, J. C. Peters, Chem. Commun. 2010, 46, 398-400; c) J. P. Bigi, T. E. Hanna, W. H. Harman, A. Chang, C. J. Chang, Chem. Commun. 2010, 46, 958-960; d) C. H. Lee, D. K. Dogutan, D. G. Nocera, J. Am. Chem. Soc. 2011, 133, 8775-8777; e) W. R.

McNamara, Z. Han, P. J. Alperin, W. W. Brennessel, P. L. Holland, R. Eisenberg, J. Am. Chem. Soc. 2011, 133, 15368-15371; f) Y. Sun, J. P. Bigi, N. A. Piro, M. L. Tang, J. R. Long, C. J. Chang, J. Am. Chem. Soc. 2011, 133, 92129215; g) E. Anxolabéhère-Mallart, C. Costentin, M. Fournier, S. Nowak, M. Robert, J.-M. Savéant, J. Am. Chem. Soc. 2012, 134, 6104-6107; h) S. C. Marinescu, J. R. Winkler, H. B. Gray, Proc. Natl. Acad. Sci. U.S.A. 2012, 109, 1512715131; i) C. C. McCrory, C. Uyeda, J. C. Peters, J. Am. Chem. Soc. 2012, 134, 3164-3170; j) A. E. King, Y. Surendranath, N. A. Piro, J. P. Bigi, J. R. Long, C. J. Chang, Chem. Sci. 2013, 4, 1578-1587; k) W. M. Singh, M. Mirmohades, R. T. Jane, T. A. White, L. Hammarstrom, A. Thapper, R. Lomoth, S. Ott, Chem. Commun. 2013, 49, 8638-8640; I) S. Varma, C. E. Castillo, T. Stoll, J. Fortage, A. G. Blackman, F. Molton, A. Deronzier, M. N. Collomb, Phys. Chem. Chem. Phys. 2013, 15, 17544-17552; m) M. 
Vennampalli, G. Liang, L. Katta, C. E. Webster, X. Zhao, Inorg. Chem. 2014, 53, 10094-10100; n) D. Basu, S Mazumder, X. Shi, H. Baydoun, J. Niklas, O. Poluektov, H. B. Schlegel, C. N. Verani, Angew. Chem. Int. Ed. 2015, 54, 2105-2110; o) J. W. Jurss, R. S. Khnayzer, J. A. Panetier, K. A. El Roz, E. M. Nichols, M. Head-Gordon, J. R. Long, F. N. Castellano, C. J. Chang, Chem. Sci. 2015, 6, 4954-4972; p) A. Lewandowska-Andralojc, T. Baine, X. Zhao, J. T. Muckerman, E. Fujita, D. E. Polyansky, Inorg. Chem. 2015, 54, 4310-4321; q) J. Willkomm, N. M. Muresan, E. Reisner, Chem. Sci. 2015, 6, 2727-2736; r) B. Kandemir, L. Kubie, Y Guo, B. Sheldon, K. L. Bren, Inorg. Chem. 2016, 55, 13551357; s) A. G. Maher, G. Passard, D. K. Dogutan, R. L. Halbach, B. L. Anderson, C. J. Gagliardi, M. Taniguchi, J. S. Lindsey, D. G. Nocera, ACS Catal. 2017, 7, 3597-3606; t) S. Khandelwal, A. Zamader, V. Nagayach, D. Dolui, A. Q. Mir, A. Dutta, ACS Catal. 2019, 9, 2334-2344; u) L. Kohler, J. Niklas, R. C. Johnson, M. Zeller, O. G. Poluektov, K. L. Mulfort, Inorg. Chem. 2019, 58, 1697-1709; v) J.-W. Wang, K. Yamauchi, H.-H. Huang, J.-K. Sun, Z.-M. Luo, D.-C. Zhong, T.-B. Lu, K. Sakai, Angew. Chem. Int. Ed. 2019, 58, 10923-10927; w) J. L. Dempsey, B. S. Brunschwig, J. R. Winkler, H. B. Gray, Acc. Chem. Res. 2009, 42, 1995-2004 $\mathrm{x}) \mathrm{V}$. Artero, M. Chavarot-Kerlidou, M. Fontecave, Angew. Chem. Int. Ed. 2011, 50, 7238-7266; y) N. Kaeffer, M. Chavarot-Kerlidou, V. Artero, Acc. Chem. Res. 2015, 48 , 1286-1295; z) D. Z. Zee, T. Chantarojsiri, J. R. Long, C. J. Chang, Acc. Chem. Res. 2015, 48, 2027-2036.

[4] a) R. M. Kellett, T. G. Spiro, Inorg. Chem. 2002, 24, 23732377 ; b) B. B. Beyene, S. B. Mane, C. H. Hung, Chem. Commun. 2015, 51, 15067-15070.

[5] a) R. M. Kellett, T. G. Spiro, Inorg. Chem. 2002, 24, 23782382; b) T. Abe, F. Taguchi, H. Imaya, F. Zhao, J. Zhang, M. Kaneko, Polym. Adv. Technol. 1998, 9, 559-562; c) C. Canales, F. Varas-Concha, T. E. Mallouk, G. Ramirez, Appl. Catal. B Environ. 2016, 188, 169-176; d) A. M. Beiler, D. Khusnutdinova, B. L. Wadsworth, G. F. Moore, Inorg. Chem. 2017, 56, 12178-12185.

[6] a) J. G. Kleingardner, B. Kandemir, K. L. Bren, J. Am. Chem. Soc. 2014, 136, 4-7; b) D. J. Sommer, M. D. Vaughn, G. Ghirlanda, Chem. Commun. 2014, 50, 15852-15855.

[7] a) C. Y. Yeh, C. J. Chang, D. G. Nocera, J. Am. Chem. Soc. 2001, 123, 1513-1514; b) C. J. Chang, L. L. Chng, D. G. Nocera, J. Am. Chem. Soc. 2003, 125, 1866-1876; c) S. Samanta, K. Sengupta, K. Mittra, S. Bandyopadhyay, A. Dey, Chem. Commun. 2012, 48, 7631-7633; d) C. T. Carver, B. D. Matson, J. M. Mayer, J. Am. Chem. Soc. 2012, 134 , 5444-5447; e) D. J. Graham, D. G. Nocera, Organometallics 2014, 33, 4994-5001; f) I. Azcarate, C. Costentin, M. Robert, J. M. Saveant, J. Am. Chem. Soc. 2016, 138, 16639-16644; g) A. Rana, B. Mondal, P. Sen, S. Dey, A. Dey, Inorg. Chem. 2017, 56, 1783-1793; h) E. M. Nichols, J. S. Derrick, S. K. Nistanaki, P. T. Smith, C. J. Chang, Chem. Sci. 2018, 9, 2952-2960; i) R. Zhang, J. J. Warren, J. Am. Chem. Soc. 2020, 142, 13426-13434; j) C. G. Margarit, C. Schnedermann, N. G. Asimow, D. G. Nocera, Organometallics 2018, 38, 1219-1223; k) S. Sinha, M. Ghosh, J. J. Warren, ACS Catal. 2019, 9, 2685-2691; I) W. Zhang, W. Lai, R. Cao, Chem. Rev. 2017, 117, 3717-3797; m) B. B. Beyene, C. H. Hung, Coord. Chem. Rev. 2020, 410, $213234 ;$ n) S. Amanullah, P. Saha, A. Nayek, M. E. Ahmed, A. Dey, Chem. Soc. Rev. 2021.

[8] a) T. F. Jaramillo, K. P. Jorgensen, J. Bonde, J. H. Nielsen, S. Horch, I. Chorkendorff, Science 2007, 317, 100-102; b) C. Wang, H. Daimon, T. Onodera, T. Koda, S. Sun, Angew. Chem. Int. Ed. 2008, 47, 3588-3591; c) C. Chen, Y. Kang, Z. Huo, Z. Zhu, W. Huang, H. L. Xin, J. D. Snyder, D. Li, J. A. Herron, M. Mavrikakis, M. Chi, K. L. More, Y. Li, N. M. Markovic, G. A. Somorjai, P. Yang, V. R. Stamenkovic, Science 2014, 343, 1339-1343; d) M. S. Faber, S. Jin,
Energy Environ. Sci. 2014, 7, 3519-3542; e) E. J. Popczun, C. W. Roske, C. G. Read, J. C. Crompton, J. M. McEnaney, J. F. Callejas, N. S. Lewis, R. E. Schaak, J. Mater. Chem. A 2015, 3, 5420-5425; f) H. Mistry, A. S. Varela, S. Kuhl, P. Strasser, B. Roldan Cuenya, Nat. Rev. Mater. 2016, 1, $16009 ;$ g) Y. P. Zhu, T. Y. Ma, M. Jaroniec, S. Z. Qiao, Angew. Chem. Int. Ed. 2017, 56, 1324-1328.

[9] a) A. M. Kluwer, R. Kapre, F. Hartl, M. Lutz, A. L. Spek, A. M. Brouwer, P. W. van Leeuwen, J. N. Reek, Proc. Natl. Acad. Sci. U.S.A. 2009, 106, 10460-10465; b) C. W. Machan, J. Yin, S. A. Chabolla, M. K. Gilson, C. P. Kubiak, J. Am. Chem. Soc. 2016, 138, 8184-8193; c) M. Schulze, V. Kunz, P. D. Frischmann, F. Wurthner, Nat. Chem. 2016, 8, 576-583; d) S. Donck, J. Fize, E. Gravel, E. Doris, V. Artero, Chem. Commun. 2016, 52, 11783-11786; e) M. Gong, Z. Cao, W. Liu, E. M. Nichols, P. T. Smith, J. S. Derrick, Y. S. Liu, J. Liu, X. Wen, C. J. Chang, ACS Cent. Sci. 2017, 3, 1032-1040; f) A. N. Oldacre, A. E. Friedman, T. R. Cook, J. Am. Chem. Soc. 2017, 139, 1424-1427; g) S. S. Nurttila, R. Becker, J. Hessels, S. Woutersen, J. N. H. Reek, Chem. Eur. J. 2018, 24, 16395-16406; h) A. N. Oldacre, M. R. Crawley, A. E. Friedman, T. R. Cook, Chem. Eur. J. 2018, 24, 10984-10987; i) P. T. Smith, B. P. Benke, Z. Cao, Y. Kim, E. M. Nichols, K. Kim, C. J. Chang, Angew. Chem. Int. Ed. 2018, 57, 9684-9688; j) P. T. Smith, Y. Kim, B. P. Benke, K. Kim, C. J. Chang, Angew. Chem. Int. Ed. 2020, 59, 49024907.

[10] a) S. Pullen, H. Fei, A. Orthaber, S. M. Cohen, S. Ott, J. Am. Chem. Soc. 2013, 135, 16997-17003; b) A. J. Clough, J. W. Yoo, M. H. Mecklenburg, S. C. Marinescu, J. Am. Chem. Soc. 2015, 137, 118-121; c) S. Lin, C. S. Diercks, Y. B. Zhang, N. Kornienko, E. M. Nichols, Y. Zhao, A. R. Paris, D. Kim, P. Yang, O. M. Yaghi, C. J. Chang, Science 2015, 349, 1208-1213; d) R. Dong, M. Pfeffermann, H. Liang, Z. Zheng, X. Zhu, J. Zhang, X. Feng, Angew. Chem. Int. Ed. 2015, 54, 12058-12063; e) I. Hod, M. D. Sampson, P. Deria, C. P. Kubiak, O. K. Farha, J. T. Hupp, ACS Catal. 2015, 5, 63026309; f) E. M. Miner, T. Fukushima, D. Sheberla, L. Sun, Y. Surendranath, M. Dinca, Nat. Commun. 2016, 7, 10942; g) C. S. Diercks, S. Lin, N. Kornienko, E. A. Kapustin, E. M. Nichols, C. Zhu, Y. Zhao, C. J. Chang, O. M. Yaghi, J. Am. Chem. Soc. 2018, 140, 1116-1122.

[11] a) P. T. Smith, E. M. Nichols, Z. Cao, C. J. Chang, Acc. Chem. Res. 2020, 53, 575-587; b) A. H. Proppe, Y. G. C. Li, A. Aspuru-Guzik, C. P. Berlinguette, C. J. Chang, R. Cogdell, A. G. Doyle, J. Flick, N. M. Gabor, R. van Grondelle, S. Hammes-Schiffer, S. A. Jaffer, S. O. Kelley, M. Leclerc, K. Leo, T. E. Mallouk, P. Narang, G. S. SchlauCohen, G. D. Scholes, A. Vojvodic, V. W. W. Yam, J. Y. Yang, E. H. Sargent, Nat. Rev. Mater. 2020, 5, 828-846.

[12] a) N. M. Rue, J. L. Sun, R. Warmuth, Isr. J. Chem. 2011, 51, 743-768; b) T. Hasell, A. I. Cooper, Nat. Rev. Mater. 2016, 1 , 16053.

[13] a) T. Hasell, M. Schmidtmann, C. A. Stone, M. W. Smith, A. I. Cooper, Chem. Commun. 2012, 48, 4689-4691; b) S. Hong, M. R. Rohman, J. Jia, Y. Kim, D. Moon, Y. Kim, Y. H. Ko, E. Lee, K. Kim, Angew. Chem. Int. Ed. 2015, 54, 1324113244 ; c) X. Y. Hu, W. S. Zhang, F. Rominger, I. Wacker, R. R. Schroder, M. Mastalerz, Chem. Commun. 2017, 53, 8616-8619

[14] a) Y. Jin, B. A. Voss, R. D. Noble, W. Zhang, Angew. Chem. Int. Ed. 2010, 49, 6348-6351; b) T. Mitra, K. E. Jelfs, M. Schmidtmann, A. Ahmed, S. Y. Chong, D. J. Adams, A. I. Cooper, Nat. Chem. 2013, 5, 276-281.

[15] R. L. Greenaway, D. Holden, E. G. B. Eden, A. Stephenson, C. W. Yong, M. J. Bennison, T. Hasell, M. E. Briggs, S. L. James, A. I. Cooper, Chem. Sci. 2017, 8, 2640-2651.

[16] B. P. Benke, P. Aich, Y. Kim, K. L. Kim, M. R. Rohman, S. Hong, I. C. Hwang, E. H. Lee, J. H. Roh, K. Kim, J. Am. Chem. Soc. 2017, 139, 7432-7435. 
[17] Y. Kim, J. Koo, I. C. Hwang, R. D. Mukhopadhyay, S. Hong, J. Yoo, A. A. Dar, I. Kim, D. Moon, T. J. Shin, Y. H. Ko, K. Kim, J. Am. Chem. Soc. 2018, 140, 14547-14551.

[18] X. Yu, B. Wang, Y. Kim, J. Park, S. Ghosh, B. Dhara, R. D. Mukhopadhyay, J. Koo, I. Kim, S. Kim, I. C. Hwang, S. Seki, D. M. Guldi, M. H. Baik, K. Kim, J. Am. Chem. Soc. 2020, 142, 12596-12601.

[19] R. D. Mukhopadhyay, Y. Kim, J. Koo, K. Kim, Acc. Chem. Res. 2018, 51, 2730-2738.

[20] a) C. Costentin, J. M. Saveant, J. Am. Chem. Soc. 2018 140, 16669-16675; b) Y. H. Wang, M. L. Pegis, J. M. Mayer, S. S. Stahl, J. Am. Chem. Soc. 2017, 139, 16458-16461.

[21] T. Shinagawa, A. T. Garcia-Esparza, K. Takanabe, Sci. Rep. 2015, 5, 13801.

[22] N. Morlanés, K. Takanabe, V. Rodionov, ACS Catal. 2016, 6, 3092-3095.

[23] C. M. Hanna, C. D. Sanborn, S. Ardo, J. Y. Yang, ACS Appl. Mater. Interfaces 2018, 10, 13211-13217.

[24] M. H. Zhu, R. Q. Ye, K. Jin, N. Lazouski, K. Manthiram, ACS Energy Lett. 2018, 3, 1381-1386.

[25] a) G. Q. Zhao, K. Rui, S. X. Dou, W. P. Sun, Adv. Funct. Mater. 2018, 28, 1803291; b) A. Wagner, C. D. Sahm, E. Reisner, Nat. Catal. 2020, 3, 775-786. 